\title{
Reply to the Queries Regarding Our Article Entitled "Endovascular Repair of a Traumatic Axillary Artery Pseudoaneurysm"
}

\author{
Sreenivas Reddy
}

Received: 1 September 2009/Accepted: 10 September 2009/Published online: 15 October 2009

(C) Springer Science+Business Media, LLC and the Cardiovascular and Interventional Radiological Society of Europe (CIRSE) 2009

Regarding our article [1], I agree that a coordinated approach by the orthopedic and vascular surgeons would have been the definitive treatment. The patient and her family decided on conservative management at that time, in view of her age, and orthopedic surgery at a later date. She had numbness of the left upper limb, suggesting involvement of the brachial plexus but this did not limit her daily activities of life. She was lost to follow-up. She is now in UK. In a telephonic conversation her relatives abroad reported that she is doing well and does not want to undergo orthopedic surgery for her limb.

\section{Reference}

1. Kumar RM, Reddy SS, Sharma R et al (2009) Endovascular repair of a traumatic axillary artery pseudoaneurysm. CardioVasc Interv Radiol 32:598-600 